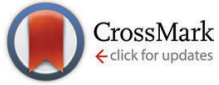

Cite this: Chem. Commun., 2015, 51, 1263

Received 30th October 2014, Accepted 26th November 2014

DOI: $10.1039 / \mathrm{c} 4 \mathrm{cc} 08594 a$

www.rsc.org/chemcomm

\section{Regio- and stereoselective synthesis of benzothiazolo-pyrimidinones via an NHC-catalyzed Mannich/lactamization domino reaction $\dagger$}

\author{
Qijian Ni, Xiaoxiao Song, Jiawen Xiong, Gerhard Raabe and Dieter Enders*
}

\begin{abstract}
An NHC-catalyzed regio- and stereoselective Mannich/lactamization domino reaction of $N$-(benzothiazolyl)imines with $\alpha$-chloroaldehydes has been developed. This new protocol provides a facile approach for the asymmetric synthesis of benzothiazolo-pyrimidinones and a pyrrolo[1,2-a]indolone in moderate to good yields (34-78\%) and excellent stereoselectivities (87-99\% ee, up to $>20: 1$ d.r.).
\end{abstract}

The tricyclic pyrimido[2,1- $b]$ benzothiazole core prevails in a wide range of bioactive molecules with remarkable biological properties, ${ }^{1}$ such as the inhibition of $c$-AMP phosphodiesterase, antineoplastic and antimalarial activity. Moreover, the isothiourea-based HBTM is used as an efficient organocatalyst and received great attention in the field of asymmetric catalysis (Fig. 1). ${ }^{2}$ Although various approaches for the synthesis of the pyrimido[2,1- $b]$ benzothiazole motif have been developed, most of them are nonstereoselective and/or need relatively harsh conditions. ${ }^{3}$

In the past decade, great advances have been achieved in the development of N-heterocyclic carbene (NHC) catalyzed organocatalytic reactions via the umpolung of aldehydes. ${ }^{4}$ Especially since the seminal studies concerning the NHC-catalyzed conjugate umpolung reactions reported by the groups of Glorius and Bode in 2004, ${ }^{5} \mathrm{NHC}$ organocatalysis has been extended for the activation of the $\beta$-carbon (homoenolate intermediate) and $\alpha$-carbon (enolate intermediate) of enals. These two kinds of intermediates used as nucleophiles reacted with a variety of reactive electrophiles to afford heterocyclic compounds such as lactones, lactams or cyclopentenes. ${ }^{6}$ It is noteworthy that aldimines behaved as excellent electrophiles in the reactions of enolate intermediates, providing the corresponding $\beta$-lactams (Scheme 1, eqn (1)). Smith et al. ${ }^{7}$ and Ye et al. ${ }^{8}$ reported an NHCcatalyzed [2+2] cycloaddition of ketenes with $N$-tosyl imines and $N$-Boc imines, respectively. Very recently, the Ye group was able

Institute of Organic Chemistry, RWTH Aachen University, Landoltweg 1,

52074 Aachen, Germany. E-mail: enders@rwth-aachen.de

$\dagger$ Electronic supplementary information (ESI) available. CCDC 1029497. For ESI and crystallographic data in CIF or other electronic format see DOI: 10.1039/ c4cc08594a

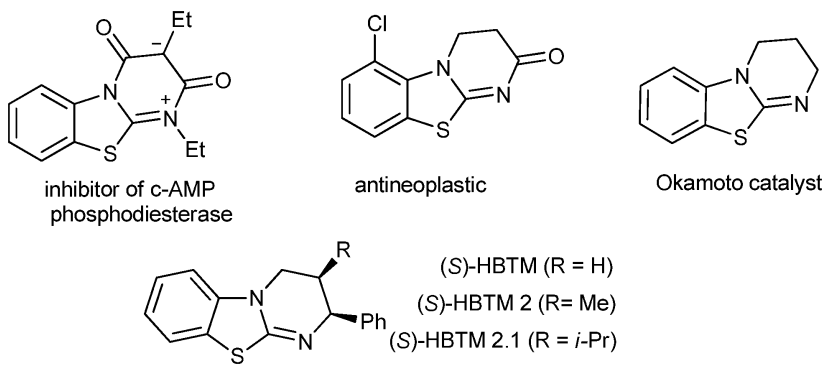

Fig. 1 Examples of pyrimido[2,1-b]benzothiazole derivatives.

to carry out Staudinger reactions of ketenes with isatin-derived ketimines, yielding spirocyclic oxindolo- $\beta$-lactams. ${ }^{9}$ We envisioned that 2-benzothiazolimine 1a in combination with an azolium enolate could not only produce the $\beta$-lactam $\mathbf{4}$, but also provide access to benzothiazolo-pyrimidinone 3 through a formal $[4+2]$ annulation (Scheme 1, eqn (2)). Obviously, influencing the regioselectivity of the reaction site of the intermediate ambident anions is the greatest challenge in order to improve the ratio of $\mathbf{3 / 4}$ in the Mannich/lactamization domino reaction.

To test our hypothesis, we initially checked several triazolium precatalysts $\mathbf{A}-\mathbf{C}$ in the model reaction of 2-benzothiazolimine 1a with 2-chloro-3-phenylpropanal (2a) at room temperature.

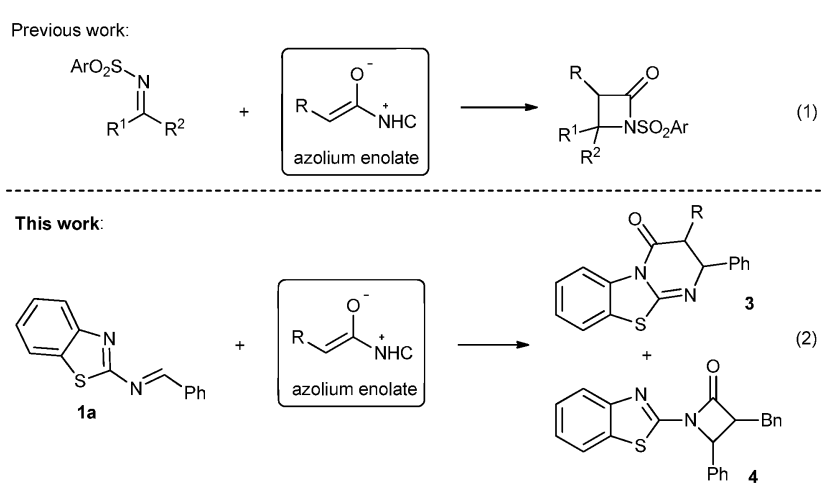

Scheme 1 Reactions of imines with NHC-bound enolate intermediates. 
Table 1 Optimization of the reaction conditions ${ }^{a}$

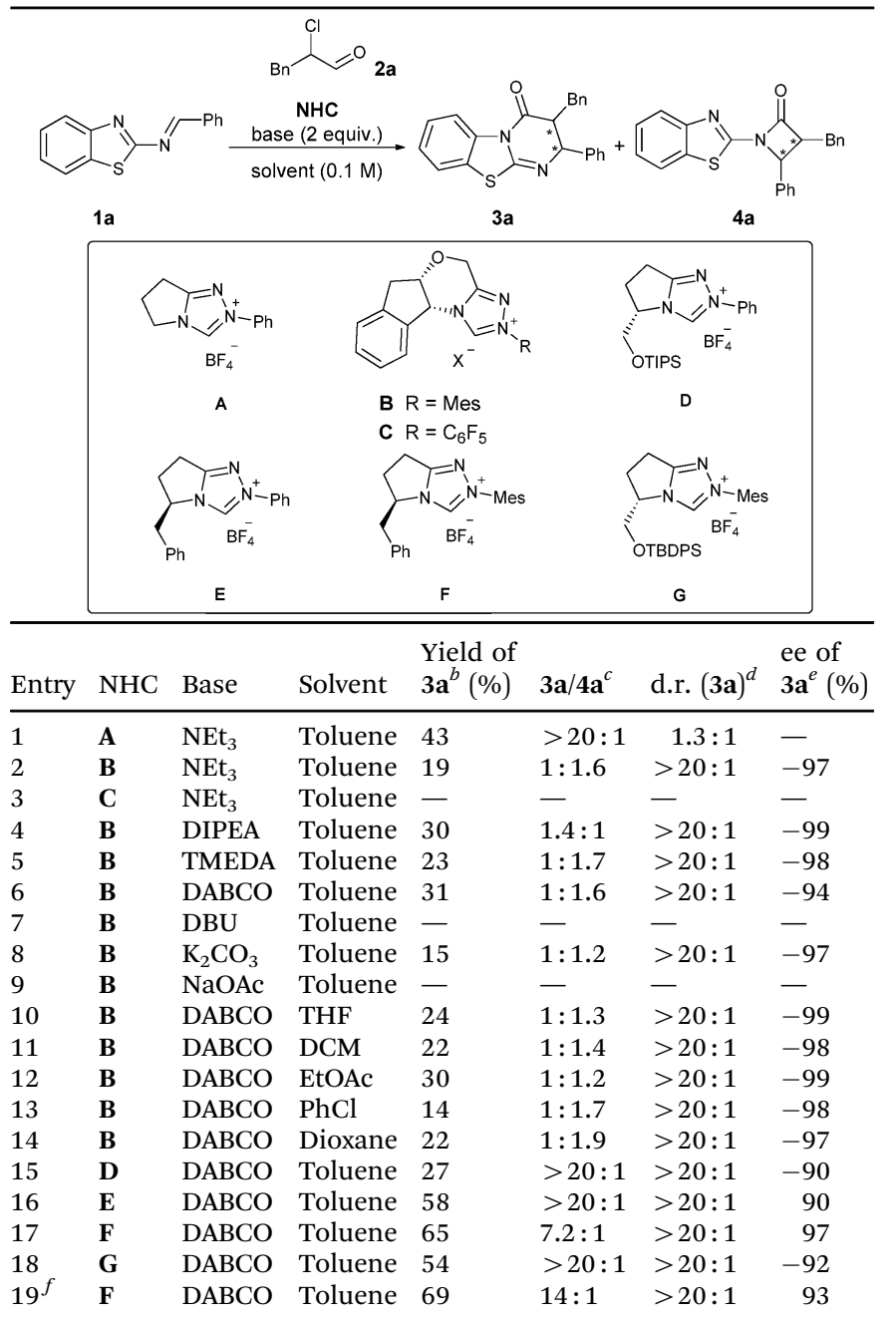

${ }^{a}$ Reaction conditions: $1 \mathrm{a}(0.1 \mathrm{mmol}), 2 \mathrm{a}(0.2 \mathrm{mmol})$, NHC $(0.01 \mathrm{mmol})$, base $(0.22 \mathrm{mmol})$, solvent $(1 \mathrm{~mL}), \mathrm{rt}, 16 \mathrm{~h} .{ }^{b}$ Yields of isolated $3 \mathrm{a}$ after flash column chromatography. ${ }^{c}$ Ratio based on isolated yields. ${ }^{d}$ Determined by ${ }^{1} \mathrm{H}$ NMR. ${ }^{e}$ The ee value was determined by HPLC on a chiral stationary phase. ${ }^{f}$ Addition of $4 \AA$ MS. DIPEA $=N, N$-diisopropylethylamine, TMEDA $=$ tetramethylethylenediamine, DABCO = 1,4-diazabicyclo[2.2.2]octane, DBU = 1,8-diazabicyclo-[5.4.0]undec-7-ene, Mes = 2,4,6-trimethylphenyl, TBDPS = tert-butyldiphenylsilyl, and TIPS = triisopropylsilyl.

We found that the chiral triazolium salt $\mathbf{B}$ resulted in an excellent stereoselectivity for ent-3a (97\% ee, $>20: 1$ d.r.), albeit with a low yield (19\%) and regioselectivity (Table 1, entry 2 ). Attempting to improve the regioselectivity and the yield of ent-3a, we next tested a series of bases, but no satisfying improvement was achieved (Table 1, entries 4-9). Solvent screening led to no improvement in yield and selectivity (Table 1, entries 10-14). After the screening of the base and solvent, DABCO in combination with toluene turned out to give the highest yield of ent-3a (31\%), maintaining the excellent stereoselectivity and the low regioselectivity as well (Table 1, entry 6). Notably, the triazolium salt A provided rac-3a in $43 \%$ yield exclusively, even though with a drastically decreased d.r. (Table 1, entry 1). Therefore we further screened a series of pyrrolidinone-derived triazolium salts D-G. To our delight, a dramatic improvement in both yield
Table 2 Substrate scope ${ }^{a}$

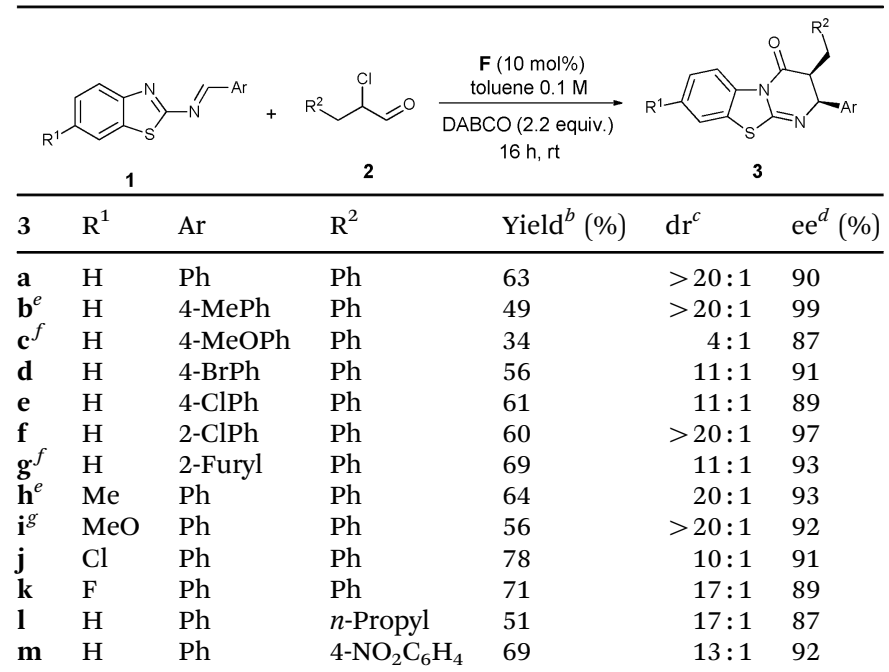

${ }^{a}$ Reaction conditions: 1 (0.5 mmol), $2(1.0 \mathrm{mmol}), \mathbf{F}(0.05 \mathrm{mmol})$, DABCO $(1.1 \mathrm{mmol})$, toluene $(5 \mathrm{~mL}), 4 \AA \mathrm{MS}, \mathrm{rt}, 16 \mathrm{~h} .{ }^{b}$ Yield of isolated 3 after flash column chromatography. ${ }^{c}$ Determined by ${ }^{1} \mathrm{H}$ NMR. ${ }^{d}$ The ee value was determined by HPLC on a chiral stationary phase. ${ }^{e}$ The reaction time is 24 h. ${ }^{f}$ Performed at $40{ }^{\circ} \mathrm{C} .{ }^{g}$ The reaction time is $48 \mathrm{~h}$.

and regioselectivity was obtained (Table 1, entries 15-18). The NHC-catalyzed reaction based on the triazolium salt $\mathbf{F}$ afforded cycloadduct $\mathbf{3 a}$ in a better yield but with relatively low regioselectivity (Table 1, entry 17). After using 4 A MS as an additive, the yield (69\%) and regioselectivity (14:1) improved further, but the enantioselectivity (93\% ee) decreased slightly (Table 1, entry 19).

Next we investigated the substrate scope of this protocol on a $0.5 \mathrm{mmol}$ scale. As shown in Table 2, a wide range of 2-benzothiazolimines 1 with diverse electronic and steric properties were first explored. The use of 2-benzothiazolimines 1a afforded the desired $3 a$ in $63 \%$ yield with $>20: 1$ d.r. and $90 \%$ ee (Table 2, 3a). Electron-donating substituents such as 4-Me and 4-OMe on the Ar group reduced the electrophilicity of the imine carbon, which led to lower yields and even the diasteroselectivity in $\mathbf{3 c}$ (Table 2, 3b,c). In the case of electronwithdrawing groups such as $4-\mathrm{Br}, 4-\mathrm{Cl}$ and $2-\mathrm{Cl}$, the reactions gave the desired cycloadducts 3d-f in good yields and with good to excellent diastereo- and enantioselectivities. The introduction of a heterocyclic furyl group on the Ar position gave compatible results, affording the corresponding product $\mathbf{3 g}$ in $69 \%$ yield, $11: 1$ d.r. and 93\% ee under an elevated temperature. Several electron-donating and electron-withdrawing substituents such as $\mathrm{R}^{1}$ were also investigated, yielding the cycloadducts $\mathbf{3 h}-\mathbf{k}$ in good yields and excellent stereoselectivities. We then varied the $\alpha$-chloroaldehyde moiety. An aliphatic linear $\alpha$-chloroaldehyde reacted smoothly with a slight loss of yield and with a reasonable ee value (Table 2, 31). When a paranitrophenyl group instead of $\mathrm{Ph}$ as $\mathrm{R}^{2}$ was used, a better result in terms of yield and ee was obtained (Table 2, 3m).

The relative configuration of the major diastereomer $3 \mathbf{a}$ was determined by NOE measurements (see ESI $\dagger$ ), which is in accordance with the absolute configuration of compound $\mathbf{3 e}$ determined by X-ray crystal structure analysis (Fig. 2). ${ }^{10}$ 


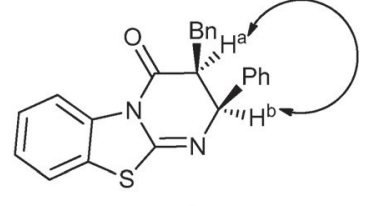

$3 a$

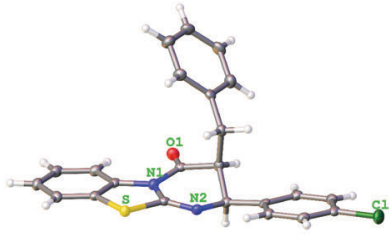

Fig. 2 Determination of the relative configuration by NOE (3a) and of the absolute configuration by $\mathrm{X}$-ray crystal structure analysis (3e).

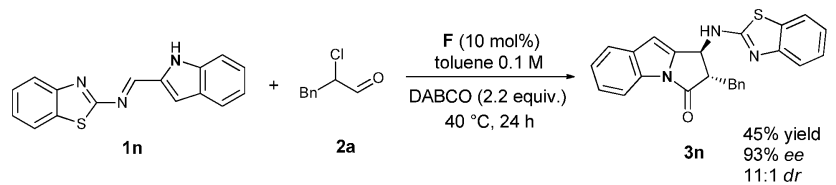

Scheme 2 Asymmetric synthesis of $3 n$ via an NHC-catalyzed $[2+3]$ annulation.

We then tried to extend the substrate scope by employing a 2-indolyl group on the Ar position. In this case, after the Mannich reaction, there are three nucleophilic $\mathrm{N}$-sites for the subsequent lactamization. Interestingly, only the trans-pyrrolo[1,2-a]indolone 3n was obtained via cyclization of the indole $\mathrm{N}$-anion with the acylazolium intermediate with acceptable yield (45\%) and excellent stereoselectivity (93\% ee, 11 : 1 d.r.) (Scheme 2).

With the substrate scope and stereochemical outcome in hand, we propose a plausible catalytic cycle via a stepwise reaction sequence. As shown in Scheme 3, the nucleophilic

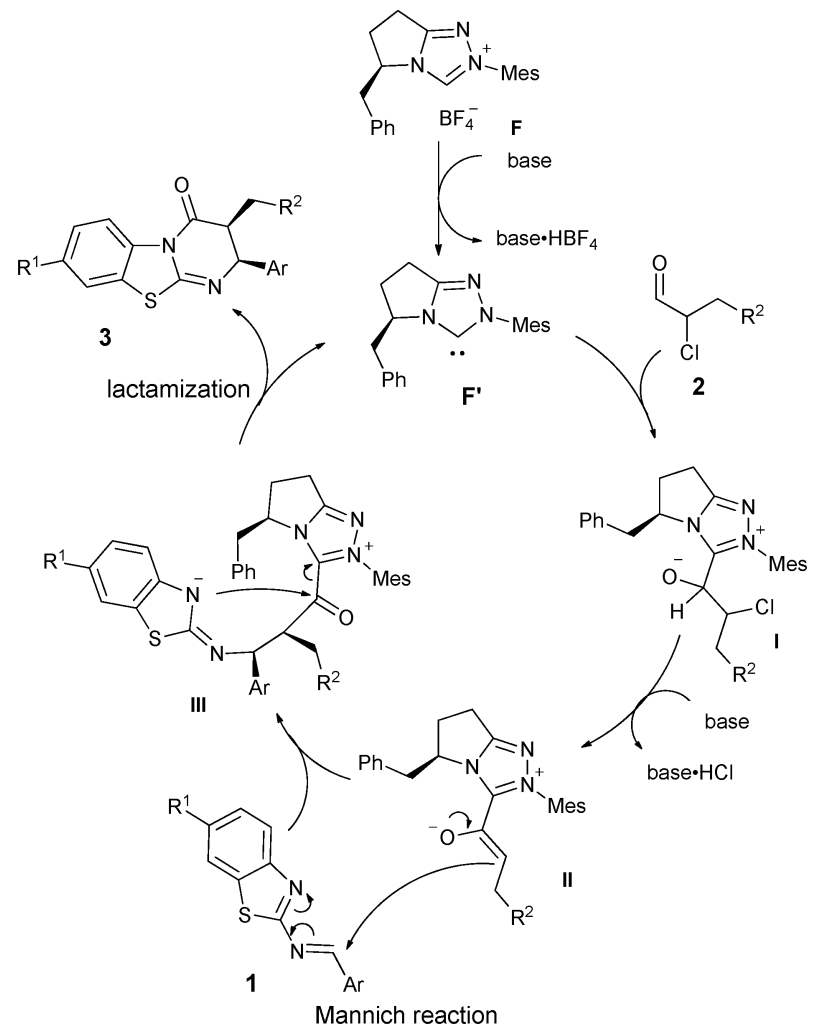

Scheme 3 Proposed mechanism of the reaction. addition of NHC to $\alpha$-chloroaldehyde gives rise to the intermediate I, followed by base assisted $\mathrm{HCl}$-elimination to provide the enolate species II. This azolium-enolate then reacts on its $R e$-face with 2-benzothiazolimine 1 via a Mannich reaction to afford the adduct III with cis selectivity. Finally, the benzothiazole $\mathrm{N}$-anion then cyclizes with the acylazolium intermediate liberating the NHC catalyst and producing the desired benzothiazolopyrimidinone 3 in cis configuration.

In conclusion, we have developed an asymmetric NHCorganocatalyzed annulation of 2-benzothiazolimines with $\alpha$-chloroaldehydes, producing the desired benzothiazolopyrimidinones in moderate to good yields with excellent regioand stereoselectivities. Particularly noteworthy is the reaction of indolyl-bound 2-benzothiazolimine with 2-chloro-3-phenylpropanal. This version of the protocol leads to the formation of pyrrolo$[1,2-a]$ indolone with high regioselectivity and excellent stereoselectivity. Further applications of this protocol in the scope and application are ongoing in our laboratory.

We are grateful for the financial support from the European Research Council (ERC Advanced Grant 320493 “DOMINOCAT”). Q. Ni and X. Song thank the China Scholarship Council for a fellowship.

\section{Notes and references}

1 (a) R. A. Glennon, J. J. Gaines and M. E. Rogers, J. Med. Chem., 1981, 24, 766-769; (b) R. A. Glennon, S. M. Tejani-Butt, W. Padgett and J. W. Daly, J. Med. Chem., 1984, 27, 1364-1367; (c) A. K. Bhattacharjee, M. G. Hartell, D. A. Nichols, R. P. Hicks, B. Stanton, J. E. van Hamont and W. K. Milhous, Eur. J. Med. Chem., 2004, 39, 59-67; (d) G. Shukla, A. K. Tiwari, V. K. Singh, A. Bajpai, H. Chandra and A. K. Mishra, Chem. Biol. Drug Des., 2008, 72, 533-539; (e) M. A. El-Sherbeny, Arzneim. Forsch., 2000, 50, 848-853.

2 (a) V. B. Birman and X. Li, Org. Lett., 2008, 10, 1115-1118; (b) C. Joannesse, C. P. Johnston, C. Concellón, C. Simal, D. Philp and A. D. Smith, Angew. Chem., Int. Ed., 2009, 48, 8914-8918; (c) E. R. T. Robinson, C. Fallan, C. Simal, A. M. Z. Slawin and A. D. Smith, Chem. Sci., 2013, 4, 2193-2200; (d) L. C. Morrill, J. Douglas, T. Lebl, A. M. Z. Slawin, D. J. Fox and A. D. Smith, Chem. Sci., 2013, 4, 4146-4155; (e) D. G. Stark, L. C. Morrill, P.-P. Yeh, A. M. Z. Slawin, T. J. C. O'Riordan and A. D. Smith, Angew. Chem., Int. Ed., 2013, 52, 11642-11646; $(f)$ P.-P. Yeh, D. S. B. Daniels, D. B. Cordes, A. M. Z. Slawin and A. D. Smith, Org. Lett., 2014, 16, 964-967; $(g)$ L. C. Morrill, L. A. Ledingham, J.-P. Couturier, J. Bickel, A. D. Harper, C. Fallan and A. D. Smith, Org. Biomol. Chem., 2014, 12, 624-636.

3 (a) K.-C. Liu and B.-J. Shih, Arch. Pharm., 1985, 318, 276-278; (b) J. Cyrener and K. Burger, Monatsh. Chem., 1995, 126, 319-331; (c) J. M. Mellor and H. Rataj, Tetrahedron Lett., 1996, 37, 2619-2622; (d) R. F. Ambartsumova, Chem. Heterocycl. Compd., 1997, 33, 859-864; (e) A. L. Krasovsky, A. M. Moiseev, V. G. Nenajdenko and E. S. Balenkova, Chem. Heterocycl. Compd., 2004, 40, 667-675; $(f)$ A. B. Atar, Y. S. Jeong and Y. T. Jeong, Tetrahedron, 2014, 70, 5207-5213.

4 For selected reviews, see: (a) D. Enders and T. Balensiefer, Acc. Chem. Res., 2004, 37, 534-541; (b) D. Enders, O. Niemeier and A. Henseler, Chem. Rev., 2007, 107, 5606-5655; (c) V. Nair, S. Vellalath and B. P. Babu, Chem. Soc. Rev., 2008, 37, 2691-2698; (d) A. T. Biju, N. Kuhl and F. Glorius, Acc. Chem. Res., 2011, 44, 1182-1195; (e) J. Izquierdo, G. E. Hutson, D. T. Cohen and K. A. Scheidt, Angew. Chem., Int. Ed., 2012, 51, 11686-11698; (f) A. Grossmann and D. Enders, Angew. Chem., Int. Ed., 2012, 51, 314-325; $(g)$ X. Bugaut and F. Glorius, Chem. Soc. Rev., 2012, 41, 3511-3522; $(h)$ H. U. Vora, P. Wheeler and T. Rovis, Adv. Synth. Catal., 2012, 354, 1617-1639; (i) S. J. Ryan, L. Candish and D. W. Lupton, Chem. Soc. Rev., 2013, 42, 4906-4917; ( $j$ ) M. N. Hopkinson, C. Richter, M. Schedler and F. Glorius, Nature, 2014, 510, 485-496. 
5 (a) C. Burstein and F. Glorius, Angew. Chem., Int. Ed., 2004, 43, 6205-6208; (b) S. S. Sohn, E. L. Rosen and J. W. Bode, J. Am. Chem. Soc., 2004, 126, 14370-14371.

6 For examples employing NHC-derived enolates or homoenolates, see: (a) B. Cardinal-David, D. E. A. Raup and K. A. Scheidt, J. Am. Chem. Soc., 2010, 132, 5345-5347; (b) T.-Y. Jian, P.-L. Shao and S. Ye, Chem. Commun., 2011, 47, 2381-2383; (c) T.-Y. Jian, L.-H. Sun and S. Ye, Chem. Commun., 2012, 48, 10907-10909; (d) J. Dugal-Tessier, E. A. O'Bryan, T. B. H. Schroeder, D. T. Cohen and K. A. Scheidt, Angew. Chem., Int. Ed., 2012, 51, 4963-4967; (e) X. Zhao, K. E. Ruhl and T. Rovis, Angew. Chem., Int. Ed., 2012, 51, 12330-12333; $(f)$ J. Mo, R. Yang, X. Chen, B. Tiwari and Y. R. Chi, Org. Lett., 2012, 15, 50-53; (g) H. Lv, B. Tiwari, J. Mo, C. Xing and Y. R. Chi, Org. Lett., 2012, 14, 5412-5415; (h) J. Izquierdo, A. Orue and K. A. Scheidt, J. Am. Chem. Soc., 2013, 135, 10634-10637; (i) X. Chen, X. Fang and
Y. R. Chi, Chem. Sci., 2013, 4, 2613-2618; ( $j$ ) E. O. B. McCusker and K. A. Scheidt, Angew. Chem., Int. Ed., 2013, 52, 13616-13620; (k) Q. Ni, H. Zhang, A. Grossmann, C. C. J. Loh, C. Merkens and D. Enders, Angew. Chem., Int. Ed., 2013, 52, 13562-13566; (l) C. Guo, M. Schedler, C. G. Daniliuc and F. Glorius, Angew. Chem., Int. Ed., 2014, 53, 10232-10236; (m) J.-L. Li, B. Sahoo, C.-G. Daniliuc and F. Glorius, Angew. Chem., Int. Ed., 2014, 53, 10515-10519; (n) M. Wang, Z.-Q. Rong and Y. Zhao, Chem. Commun., 2014, 50, 15309-15312.

7 N. Duguet, C. D. Campbell, A. M. Z. Slawin and A. D. Smith, Org. Biomol. Chem., 2008, 6, 1108-1113.

8 Y.-R. Zhang, L. He, X. Wu, P.-L. Shao and S. Ye, Org. Lett., 2008, 10, 277-280.

9 H.-M. Zhang, Z.-H. Gao and S. Ye, Org. Lett., 2014, 16, 3079-3081.

10 CCDC 1029497 contains the supplementary crystallographic data for compound $3 \mathrm{e}$ reported in this communication. 